\title{
LOS TRAFICANTES DE DROGAS ANTE EL DERECHO
}

\author{
Hugo Tagle Martínez \\ Profesor Filosofía del Derecho
}

Autoridades civiles y eclesiásticas, como particulares en general, manifiestan creciente preocupación por el aumento sostenido del consumo de drogas líquidas y sólidas que afecta a cada vez más amplios sectores de nuestra comunidad.

Este hecho es considerado unánimemente un grave mal, tal vez el más profundo mal que pueda dañar a una sociedad, no sólo a quienes las consumen, sino que también a sus familiares y a toda la sociedad. Que ello sea así nadie puede razonablemente negarlo, ya que el efecto que la droga produce en quienes llegan a consumirla habitualmente - que, salvo excepciones son todos quienes empiezan a probarla, en especial las drogas sólidas consiste en definitiva en la destrucción de la persona del consumidor, no sólo de sus facultades superiores del entendimiento y la voluntad, sino que también de su ser psíquico y físico.

Esta destrucción de la persona del drogadicto no sólo le perjudica a él, sino que también, como es comprensible, a sus familiares - hijos o padres, según el caso, principalmente - y en definitiva a toda la sociedad, la que debe soportar y si le es posible auxiliar material y espiritualmente a este enfermo, destinando recursos que podrían dirigirse a satisfacer otras necesidades.

Si el anterior es el resultado final del consumo de drogas, al que se llega poco después de su inicio, lo que generalmente es conocido por el que empieza a consumirla como por quienes la rechazan, es imperioso, si queremos en lo posible eliminar esta grave enfermedad, que nos preguntemos porqué razón hay consumidores como también productores, distribuidores y vendedores de drogas, ya que si acertamos en encontrar la respuesta a esta pregunta entraremos al camino que nos permita resolver esta cada vez más extendida enfermedad.

Quien consume drogas, así me parece, lo hace porque cree encontrar en ellas una fuente de felicidad o de potenciación de sus facultades, a la que naturalmente todos tendemos, pues todo ser humano está determinado, esto es orientado de modo necesario e inevitable, tanto a morir cuanto a la felicidad o plenitud de su ser.

En esta ansia irrefrenable de felicidad, puesta en el corazón del hombre por el mismo Dios y por tanto buena, está el origen de la solicitud por la droga por parte del hombre que conociendo lo que anhela no sabe lo que le conviene para conquistarla.

En esta ceguera del hombre que le impide ver o conocer qué le conviene para ser feliz, la educación, que ha dejado de ser tal para quedar en sólo una deficiente instrucción y la propaganda tan influyente en nuestros días, tienen una responsabilidad preponderante, ya que por omisión en el caso de la primera, incluida la pérdida religiosa, como por acción en el caso de la segunda, le presentan bienes inadecuados e incluso falsos para conquistar 
la felicidad anhelada, que no solo lo alejan de ella, sino que, como no puede ser de otro modo, lo hunden en el desconcierto y la desesperanza.

Al llegar a este estado, la droga - sea líquida o sólida - le es presentada a quien ha caído a este nivel como la panacea que lo sacará de este pozo y lo elevará a un estado superior de bienestar, plenitud o felicidad, lo que podrá ser cierto por un corto tiempo y obtenido artificialmente, para después caer en un estado de mayor insatisfacción, lo que continuará progresivamente hasta concluir con la destrucción completa del drogadicto.

Por otra parte, al productor de droga - y nos referimos principalmente al de drogas sólidas - como el traficante y oferente de las mismas, le afecta el mismo mal que al consumidor, aún cuando reducido inicialmente a un solo aspecto, cual es el de obtener riqueza material - bien que es el más bajo de todos - por cualquier medio, que en este caso es el más censurable y criminal, pues consiste en conquistarla por medio de la reducción a la esclavitud del consumidor del producto, que concluye como lo hemos dicho, con su destrucción personal e incluso muerte, que daña además gravemente a su familia y a toda la sociedad.

Los bienes naturales, para qué decir aquellos falsos o mal interpretados o vividos, no son suficientes para satisfacer el ansia de felicidad del hombre, que en desgracia para él, son prácticamente los únicos que la cultura de hoy - mejor dicho incultura - le presenta; por consiguiente, si queremos sanar al enfermo hombre de nuestro tiempo - no sólo a los actuales drogadictos, sino que a todos que lo somos potencialmente - debemos presentarle, primordialmente, un bien superior y distinto que pueda, por su riqueza inconmensurable, satisfacer esa ansia de felicidad del hombre, que no es colmada con bienes materiales e incluso espirituales de orden natural. Ese bien existe - aún cuando es el gran desconocido para muchos - y es Dios, el único que puede colmar el anhelo de felicidad del hombre; por ello es que San Agustín, que participó de todos los placeres, aún cuando no de la droga que hoy conocemos, desilusionado de ellos exclamó: "Oh Señor, nos ha creado para Tí e insatisfecho está nuestro corazón hasta tanto no descanse en Tí."

En el conocimiento de Dios, que necesariamente engendra el amor a El y que como efecto ordena toda nuestra vida a El y con nuestros semejantes y las cosas, está la solución verdadera, el remedio principal al mal de la droga y de todos los males morales.

Dar a conocer a Dios consiste en hablar de su poder, de su amor y de su justicia, que son infinitos; consiste en mostrarlo como una persona que es todopoderosa, que ha creado todo cuanto existe y que a todas las cosas les ha dado una esencia y fin, su salvación eterna, la que sólo conseguirá si cumple la ley de conducta que le ha fijado, pero que si no la cumple se perjudicará en esta vida y en último término se condenará a la muerte eterna, ya que por la comisión de delitos graves, que son los pecados mortales, el hombre merece un castigo no sólo civil o temporal, sino que también religioso y eterno, el que aplicará Dios mismo, pues El es el último juez de todos nuestros actos, a quien nadie puede engañar.

La conciencia de que respondemos ante Dios por todos nuestros actos es el mejor medio para que nos orientemos hacia el bien y nos apartemos del mal y como esta conciencia está debilitada e incluso desaparecida del hombre de nuestro tiempo, es necesario establecerla, como tarea prioritaria, pues el mejor medio para sanar este mal, como así también todos los males morales. 
Pero como somos realistas, pensamos que también es necesario recurrir a medios naturales que sirvan como auxiliares eficaces al remedio principal; de éstos se habla hoy día más que de aquél, a pesar de lo cual insistiremos sobre los mismos aún cuando son remedios secundarios, en los cuales es posible distinguir distintas jerarquías.

El primero y más importante es el verdadero ideal de hombre que se predique. Si se presenta como ideal de hombre al hedonista, al que busca sólo o principalmente bienes materiales, como ocurre hoy día, se abre la puerta al consumo de drogas y a todos los demás vicios; por el contrario, si se muestra como ideal de hombre al santo, en primer lugar, y al sabio y al héroe, secundariamente, se le cierra la puerta al consumo de drogas y a todos los vicios y mediocridades y se la abre al verdadero bien del hombre y de la sociedad.

El segundo es conseguir que los matrimonios sean estables, no por un tiempo, sino que para siempre y que los cónyuges den principalmente amor verdadero a sus hijos y con ello educación antes que instrucción y bienes materiales, ya que un matrimonio feliz hará felices a sus hijos y con seguridad los hará inmunes a la tentación de la droga.

El tercero consiste que la educación formal, que es aquella que se da en la enseñanza básica, media, técnica y superior sea verdaderamente educación y no tan solo instrucción, esto es, conocimiento del hombre, de su origen, naturaleza, fin y medios para conseguirlo y no sólo conocimiento de las cosas como es hoy día.

El cuarto consiste en conseguir que la educación informal, así denominada y que es aquella que da la prensa, radio, cine y televisión, no se haga sobre la base de exaltar bienes que se contrapongan, por la importancia que se les da o peor aún, por ser falsos, a los que la educación formal debe dar.

El quinto consiste en fomentar, otorgando el Estado todas las mayores facilidades, la práctica de actividades creadoras como son las artísticas, entendiendo por tales la música y el deporte, principalmente, no sólo para una élite de profesionales que compitan nacional e internacionalmente, sino que más bien para toda la juventud.

Los anteriores medios son preventivos del mal de la droga - y de todo mal moral - y por consiguiente los más importantes, ya que es mejor prevenir, anticipándose para evitar un mal, que actuar para curarlo una vez producido; pero como el mal de la droga - como todos los males, salvo el primero - es histórico en el sentido de recibido como un legado que la sociedad ha heredado en algunos de sus integrantes, es necesario agregar a los anteriores medios preventivos algunos curativos, que cautericen castigando a quienes sean culpables en este mal, para impedir o al menos dificultar que continúe propagándose.

En primer lugar, los principales partícipes del mal de la droga son sus productores, los traficantes de ella al por mayor o distribuidores y los vendedores de la misma al por menor, pues todos ellos son quienes hacen posible su consumo e incluso lo fomentan; son los victimarios de este mal pues lo causan.

En segundo lugar, los principales responsables que tienen el deber de aplicar un remedio jurídico para castigar a los anteriores, que son delincuentes para la sociedad civil y pecadores para la sociedad religiosa, son las autoridades civil y religiosa, respectivamente, ya que una y otra son las encargadas por Dios para procurar el bien común de sus respectivas comunidades - bien común natural y sobrenatural que están estrechamente vinculados - por lo que tiene la obligación, por la que responden ante Dios, de actuar con la 
energía necesaria para obtenerlos, dictando y aplicando las normas de derecho conducentes al fin que se pretende, que en este caso particular es la eliminación de la producción, distribuciones y venta de la droga.

En tercer lugar, pienso que debiera considerarse que promover el consumo de drogas es, ordinariamente, el más grave delito y pecado, en esta última calificación, de orden social, que pueda cometer el hombre, ya que por él está destruyendo, está matando lentamente a quien empieza a consumirla; es el delito de homicidio espiritual, que incluso puede llegar a ser físico, difícilmente recuperable en el primero, que además daña gravemente a su familia y a toda la sociedad.

En cuarto y último lugar, ¿a qué castigo se hace acreedor un hombre que comete tal delito y pecado de modo conciente y voluntario, sin que exista ninguna atenuante que disminuya su responsabilidad y menos aún una eximente que le deje libre de culpa?.

Comenzando por el castigo al pecado y al pecador, de competencia de la autoridad eclesiástica como representante de Dios, el pecado objetivo es de los más graves, pues, a mi juicio, es asimilable al homicidio físico, al homicidio de Abel por Caín y el pecado subjetivo o del pecador, también lo es, supuesta la conciencia y voluntariedad en su comisión; es pecado mortal que mata el alma del pecador, por el cual éste se hace merecedor a la pena capital de eterna condenación, a la pérdida de la vida eterna, así como el que escandaliza a inocentes.

Terminando por el castigo al delito y al delincuente, de competencia de la autoridad civil, también como representante de Dios, el delito objetivo que consiste en producir, distribuir y vender droga, es de los más graves, sino el más grave, pues a mi juicio es asimilable al homicidio físico, aún cuando no instantáneo, y así debiera establecerlo la legislación penal, ya que como lo hemos dicho y en esta afirmación no hay error, el consumo de droga mata espiritualmente al drogadicto; el delito subjetivo o del delincuente también lo es, supuesta la conciencia y voluntariedad en su comisión y la inexistencia de atenuantes y eximentes; es delito mortal que mata el alma del delincuente y por el que se aparta de la sociedad y por el cual se hace merecedor a la pena capital de pérdida de la vida temporal, de acuerdo a la sentencia bíblica de que al que a hierro mata a hierro ha de morir; ahora bien, si se estima que no es prudente aplicar la pena de muerte a tan grave delito, pienso que se podría aplicar otra, no la de cárcel, ya que las cárceles se harán insuficientes para recibir a estos delincuentes, sino que otra, que dejándolos en libertad, les imposibilite seguir delinquiendo, que consiste en aplicar el principio universal de "por donde pecas, pagas", esto es, convertir en drogadictos a quienes cometen el delito de producir, distribuir y vender drogas, con lo que consumirían la droga que producen, distribuyen y venden. 